\title{
Stress-strain analysis of specimens subjected to tensile loading during moisture uptake
}

\author{
A. Mintzas ${ }^{1}$, R. M. Guedes ${ }^{2}$, and A. Aniskevich ${ }^{1 *}$ \\ ${ }^{1}$ Institute of Polymer Mechanics, University of Latvia, 23 Aizkraukles str., Riga, LV-1006 \\ Latvia, andrey.aniskevich@pmi.lv, phone +371-67543303 \\ ${ }^{2}$ INEGI - EXPMAT - Experimental Mechanics and New Materials \& Department of Mechanical \\ Engineering, Faculty of Engineering of the University of Porto, 4200-465 Porto, Portugal, \\ rmguedes@fe.up.pt
}

\begin{abstract}
A robust and efficient numerical method for the calculation of the internal stress state that develops within structures subjected to mechanical and steady state or transient hygroscopic loading conditions, has been developed. The method encompasses a layer by layer approach whereby the structure is discretized into plies with different material properties corresponding to the different ply moisture content. The proposed method has been validated against finite element solutions, and results from its application on a fully characterized EDT (technical name) polymer binder are presented. The impact of the moisture induced viscoelastic behaviour on the structural response of the case studied is highlighted and discussed. The approach could be used for different structures operated both open-air and indoor in automotive, marine, airspace, and other applications, e.g. for interior parts in the automobile industry.
\end{abstract}

Keywords: moisture sorption, transient hygroscopic conditions, viscoelasticity, epoxy matrix

\section{Introduction}

Over the last decades, polymers and reinforced polymer composites are increasingly used in the design of aerospace, automobile, marine and other civil structures. A common feature of all these structures is that they operate under open-air conditions and are thus likely to be exposed to humid environments. It is well known that polymer and polymer-based materials are susceptible to moisture sorption which has in turn a detrimental effect on their mechanical and physical properties (Perov \& Kruzhkova 1991), (Aniskevich \& Jansons 1998), (Lin \& Chen 2005). It is therefore apparent that moisture induced effects should be taken into consideration during the design process.

Real structures are usually subjected to transient hygroscopic loading conditions (e.g. day and year cycles) and even in the case where stationary conditions apply, sorption process may take years before moisture equilibrium is reached. As a consequence, a variable stress profile arises within the structure which can induce damage (Perreux \& Suri 1997), (Weitsman \& Elahi 2000) and can eventually lead to failure.

The first step towards the calculation of the moisture induced stresses is the determination of moisture sorption kinetics via the application of an adequate diffusion predictive model. A wide number of models have been proposed in the literature a summary of which can be found in

\footnotetext{
* Corresponding author.
} 
Mintzas, A., Guedes, R.M. and Aniskevich, A. (2015) 'Stress-strain analysis of specimens subjected to tensile loading during moisture uptake', Int. J. Automotive Composites, Vol. 1, Nos. 2/3, pp.205-222.

(Yagoubi et al. 2012), (Glaskova et al. 2007). Among these, the classical Fickian model has shown good correlation with experimental results obtained from the tests performed on resin (Aniskevich 1984), (He 2012) and uni-directionally reinforced polymer matrix (Aniskevich 1986) coupons for a wide range of temperatures and relative air humidities. This approach is thus employed in the current study as well.

Once the moisture distribution within the structure is determined, the latter can be modelled as a laminate consisting of discrete monolithic layers with different rheological properties (Shaffer \& Levitsky 1974). The different properties correspond to the different moisture content of each layer and depend on the constitutive law (Weitsman 1979), (Schapery 1974) employed. A solution for the internal stress state can then be obtained by applying classical laminate theory assumptions (Jones 1975). Such approach was followed in (Plume \& Maksimov 1992), (Plume 1994) where the problem of moisture viscoelasticity was reduced to the elasticity problem of a layered medium via the application of the Laplace transform. Once solved in the image space, the original function values of the problem were calculated by performing the inverse Laplace transform via the use of a specially developed numerical algorithm (Shtraus 1980).

Behaviour of polymer materials as a rule is much more complicate than linear viscoelastic. Some crosscoupling effects can occur. Coupling between heterogeneous wet conditions and mechanical behaviour is especially important when it comes to the identification of material properties on samples that cannot be considered as homogeneous (Quino et al. 2014), (Yagoubi et al. 2012). Meanwhile in given research coupling between the diffusion and the mechanical stress state is not taken into account as a first approach and should be added later on next step.

The objective of the research was to estimate the contribution of viscoelasticity on the stress strain behaviour of a polymer material subjected to tensile loading during moisture uptake. Given the criticality of the moisture induced internal stresses and the mathematical complexity of the Laplace transform approach (Weitsman 1979; Schapery 1974), a novel numerical method is proposed in this study. The latter can easily account for any type of static as well as transient hygroscopic loading conditions and has been validated against finite element solutions. Results from the application of the proposed method on a case study of a fully characterized epoxy (bisphenol A diglycidyl ether) polymer binder EDT (technical name) are presented. The impact of the moisture induced viscoelastic behaviour is manifested. It is well known that both moisture sorption process and viscoelastic behaviour are strongly dependent on temperature; service temperature is essentially variable for most of polymer structures, but at that moment the temperature effect is out of scope of the research and should be taken into account on the next stage.

\section{Model description}

The modelling strategy followed is divided in two main stages. At the first stage, the specimen of an originally uniform material is virtually split into $p$ number of plies with different material properties corresponding to the different moisture content of each ply as shown in Fig. 1. Fick's second law is then used for the determination of the time-dependent ply moisture content. At the second stage, constitutive models are applied at the ply level for the determination of the stress distribution within the layered specimen.

\subsection{Modelling of moisture sorption}


In this study, sorption is assumed to occur solely by diffusion and classical Fick's law is employed for the calculation of the moisture distribution within the specimen. Since the specimen's width and length are an order of magnitude greater than its thickness, onedimensional diffusion (along the $x$-axis in Fig. 1) is considered. The variation of moisture concentration with time can thus be obtained from the following partial differential equation

$\frac{\partial c}{\partial t}=\frac{\partial}{\partial x}\left(D \frac{\partial c}{\partial x}\right)$

where $c$ is the moisture concentration and $D$ is the moisture diffusion coefficient describing the rate of moisture sorption.

Provided that $D$ is independent of the moisture concentration and that long term behaviour is of primary interest (i.e. Fourier criterion $\mathrm{Fo} \geq 0.2$ where $\mathrm{Fo}=(4 D t) / h^{2}$ and $h$ is the plate thickness (Lykov 1948)) the solution for Eq. (1) can be more robustly obtained via the separation of variables method (Crank 1975). For initial $c(0<x<h, t=0)=c_{0}$ and stationary $c(x=0, x=h, t>0)=c_{\infty}$ boundary conditions, the solution is given from the following series

$c(x, t)=c_{\infty}-2 \frac{\left(c_{\infty}-c_{0}\right)}{\pi} \sum_{k=1}^{\infty} \frac{\left(1-(-1)^{k}\right)}{k} \sin \left(\lambda_{k} x\right) \exp \left(-\lambda_{k}^{2} D t\right)$

where $\lambda_{k}=\pi k / h$. By integrating Eq. (2) across the plate thickness, the moisture content of the specimen can be obtained

$w(t)=w_{\infty}-2 \frac{\left(w_{\infty}-w_{0}\right)}{\pi^{2}} \sum_{k=1}^{\infty} \frac{\left(1-(-1)^{k}\right)^{2}}{k^{2}} \exp \left(-\lambda_{k}^{2} D t\right)$,

where $w_{0}$ and $w_{\infty}$ are the initial and equilibrium moisture contents of the specimen, respectively.

For the case of initial condition $c(0<x<h, t=0)=c_{0}$ and non-stationary boundary conditions of oscillatory form that simulate day and year natural cycles i.e. $c(x=0, x=h, t>0)=$ $A_{C} \sin (w t+\Psi)+B_{C}$, the solution of Eq. (1) is given in (Plushchik \& Aniskevich 2002) 


$$
\begin{aligned}
& c(x, t)=A_{C} \sin (\omega t+\Psi)+B_{C}-\frac{2}{\pi} \sum_{k=1}^{\infty} \frac{\left(1-(-1)^{k}\right)}{k} \\
& \times\left\{\begin{array}{c}
\sin (\omega t+\Psi)+\frac{\lambda_{k}^{2} D}{\omega} \cos (\omega t+\Psi)- \\
\left.\frac{A_{C}}{\left(1+\frac{\lambda_{k}^{4} D^{2}}{\omega^{2}}\right)}\left[-\left(\sin (\Psi)+\frac{\lambda_{k}^{2} D}{\omega} \cos (\Psi) \exp \left(-\lambda_{k}^{2} D t\right)\right)\right]\right\} \sin \left(\lambda_{k} x\right), \\
-\left(C_{o}-A_{C} \sin (\Psi)-B_{C}\right) \exp \left(-\lambda_{k}^{2} D t\right)
\end{array}\right]
\end{aligned}
$$

where $A_{C}$ is the concentration oscillation amplitude, $B_{C}$ is the stationary component of moisture concentration, $\Psi$ is the initial phase shift, $\omega=2 \pi / T$ is the variation frequency and $T$ is the oscillation period. By integrating Eq. (4) across the plate thickness, the moisture content of the specimen can be obtained

$$
\begin{aligned}
& w(x, t)=A_{w} \sin (\omega t+\Psi)+B_{w}-\frac{2}{\pi^{2}} \sum_{k=1}^{\infty} \frac{\left(1-(-1)^{k}\right)^{2}}{k^{2}} \\
& \times\left\{\begin{array}{c}
\sin (\omega t+\Psi)+\frac{\lambda_{k}^{2} D}{\omega} \cos (\omega t+\Psi) \\
\left.\left(1+\frac{A_{w}}{\omega^{4} D^{2}}\right)\left[-\left(\sin (\Psi)+\frac{\lambda_{k}^{2} D}{\omega} \cos (\Psi) \exp \left(-\lambda_{k}^{2} D t\right)\right)\right]\right\}, \\
-\left(w_{o}-A_{w} \sin (\Psi)-B_{w}\right) \exp \left(-\lambda_{k}^{2} D t\right)
\end{array}\right]
\end{aligned}
$$

where $A_{w}$ and $B_{w}$ are the values of moisture content corresponding to $A_{C}$ and $B_{C}$.

\subsection{Constitutive model}

The constitutive models employed consider isotropic linear viscoelastic behaviour and are defined at the ply level. Limitations of simple and practical linear viscoelastic approach are evident - nonviscoelastic effects are neglected, stress should not overcome limit of linear viscoelasticity. But this approach allows respectively easy to modelate mechanical behaviour of the material and may be considered as the first step of the problem solving. Due to the isotropic material properties, arbitrary rotation of the $x, y$ and $z$ axes has no effect on the material behaviour, thus the plane of a single ply can be defined by the 1-2 coordinate system shown in Fig. 1. If we now consider a ply subjected to a plane stress state $\left\{\sigma_{11}, \sigma_{22}, \tau_{12}\right\}$ that varies with time, the total strains induced within the ply are given by

$$
\left\{\begin{array}{l}
\varepsilon_{11}(t) \\
\varepsilon_{22}(t) \\
\gamma_{12}(t)
\end{array}\right\}=\left[\begin{array}{ccc}
S_{11}(t) & S_{12}(t) & 0 \\
S_{12}(t) & S_{22}(t) & 0 \\
0 & 0 & S_{66}(t)
\end{array}\right]\left\{\begin{array}{c}
\sigma_{11}(t) \\
\sigma_{22}(t) \\
\tau_{12}(t)
\end{array}\right\} .
$$


Assuming that compliance terms $S_{11}(t), S_{22}(t)$, and $S_{66}(t)$ are time-dependent and that Poisson's ratio, $v$, is time independent, the total ply strains induced by an arbitrary stress history are given by

$$
\left\{\begin{array}{l}
\varepsilon_{11}(t) \\
\varepsilon_{22}(t) \\
\gamma_{12}(t)
\end{array}\right\}=\left[\begin{array}{ccc}
S & -v S & 0 \\
-v S & S & 0 \\
0 & 0 & 2(1+v) S
\end{array}\right]\left\{\begin{array}{l}
\sigma_{11}(t) \\
\sigma_{22}(t) \\
\tau_{12}(t)
\end{array}\right\}+\left\{\begin{array}{l}
\varepsilon_{11}(t) \\
\varepsilon_{22}(t) \\
\gamma_{12}(t)
\end{array}\right\}+w(t)\left\{\begin{array}{l}
\beta \\
\beta \\
0
\end{array}\right\},
$$

where

$$
\left\{\begin{array}{l}
\varepsilon_{11}(t) \\
\varepsilon_{22}(t) \\
\gamma_{12}(t)
\end{array}\right\}_{\mathrm{VE}}=\left\{\begin{array}{c}
\int_{0}^{t} \Delta S\left(\Psi-\Psi^{\prime}\right) \frac{d \sigma_{11}(\tau)}{d \tau} d \tau \\
\int_{0}^{t} \Delta S\left(\Psi-\Psi^{\prime}\right) \frac{d \sigma_{22}(\tau)}{d \tau} d \tau \\
2(1+v) \int_{0}^{t} \Delta S\left(\Psi-\Psi^{\prime}\right) \frac{d \tau_{12}(\tau)}{d \tau} d \tau
\end{array}\right\}
$$

with the corresponding reduced times $\Psi$ and $\Psi^{\prime}$ given by

$$
\Psi=\int_{0}^{t} \frac{d \tau^{\prime}}{a_{w}}, \quad \Psi^{\prime}=\int_{0}^{\tau} \frac{d \tau^{\prime}}{a_{w}},
$$

where $a_{w}$ is the horizontal moisture shift factor. The kernel $\Delta S(t)$ represents the timedependent compliance and $\beta$ is the hygroscopic expansion factor which is a function of the moisture content $w(t)$.

In order to eliminate the Volterra-type integrals, the transverse and shear compliances are expressed using Prony series, as (Gramoll et al. 1989) and (Czyz \& Szyszkowski 1990) have already discussed

$$
\Delta S(t)=\sum_{i=1}^{M} S_{i}\left(1-e^{-\lambda_{i} t}\right)
$$

where $S_{i}, \lambda_{i}, i=1 \ldots M$, are linear viscoelastic parameters.

Considering tensile loading along 2-direction (see Fig. 1) and substituting (8) into (7), $\varepsilon_{22}(t)$ strain component is given by

$\varepsilon_{22}(t)=S \sigma_{22}(t)+\sum_{i=1}^{M} \varepsilon_{i, 22}(t)+\beta w(t)$,

where 
Mintzas, A., Guedes, R.M. and Aniskevich, A. (2015) 'Stress-strain analysis of specimens subjected to tensile loading during moisture uptake', Int. J. Automotive Composites, Vol. 1, Nos. 2/3, pp.205-222.

$\varepsilon_{i, 22}(t)=S_{i, 22} \int_{0}^{t}\left(1-e^{-\lambda_{i}\left(\psi-\psi^{\prime}\right)}\right) \frac{d \sigma_{22}}{d \tau} d \tau$

If we assume linear variation of stress component $\sigma_{22}(t)$ during time step $t_{j} \leq t \leq t_{j+1}$ then

$$
\frac{d \sigma_{22}}{d t}=\frac{\sigma_{22}\left(t_{j+1}\right)-\sigma_{22}\left(t_{j}\right)}{\Delta t}
$$

If we further assume that function $\hat{g}_{i, 22}(\sigma)$ is also approximated by a linear variation then

$$
\frac{d \hat{g}_{i, 22}(\sigma)}{d t}=\frac{\hat{g}_{i, 22}\left(\sigma_{22}\left(t_{j+1}\right)\right)-\hat{g}_{i, 22}\left(\sigma_{22}\left(t_{j}\right)\right)}{\Delta t}
$$

where

$$
\hat{g}_{i, 22}(\sigma)=S_{i} \sigma_{22}
$$

By substituting (11) into (10), the following equation is obtained

$$
\varepsilon_{i, 22}\left(t_{j}\right)=\hat{g}_{i, 22}\left(\sigma_{22}\left(t_{j}\right)\right)-e^{-\lambda_{i} \theta\left(t_{j}\right)} \int_{0}^{t_{j}} e^{-\lambda_{i} \theta(\tau)} \frac{d \hat{g}_{i, 22}(\sigma)}{d \tau} d \tau
$$

where $\theta\left(t_{j}\right)=\int_{0}^{t_{j}} \frac{d \tau^{\prime}}{a_{w}}$ and $\theta(\tau)=\int_{0}^{\tau} \frac{d \tau^{\prime}}{a_{w}}$. By making use of (14), $\varepsilon_{i, 22}\left(t_{j+1}\right)$ can be expressed in terms of $\varepsilon_{i, 22}\left(t_{j}\right)$ as follows:

$$
\begin{gathered}
\mathcal{E}_{i, 22}\left(t_{j+1}\right)=\hat{g}_{i, 22}\left(\sigma_{22}\left(t_{j+1}\right)\right)-e^{-\lambda_{i}\left[\theta\left(t_{j+1}\right)-\theta\left(t_{j}\right)\right]}\left[\hat{g}_{i, 22}\left(\sigma_{22}\left(t_{j}\right)\right)-\varepsilon_{i, 22}\left(t_{j}\right)\right] \\
-\int_{t_{j}}^{t_{j+1}} e^{-\lambda_{i}\left[\theta\left(t_{j+1}\right)-\theta(\tau)\right]} \frac{d \hat{g}_{i, 22}(\sigma)}{d \tau} d \tau .
\end{gathered}
$$

The integral of (15) can be solved as

$$
\int_{t_{j}}^{t_{j+1}} e^{-\lambda_{i}\left[\theta\left(t_{j+1}\right)-\theta(\tau)\right]} \frac{d \hat{g}_{i, 22}(\sigma)}{d \tau} d \tau=\frac{\hat{g}_{i, 22}\left(\sigma_{22}\left(t_{j+1}\right)\right)-\hat{g}_{i, 22}\left(\sigma_{22}\left(t_{j}\right)\right)}{\Delta t} \cdot \frac{a_{w}\left(t_{j+1}\right)}{\lambda_{i}}\left(1-e^{-\lambda_{i} \frac{\Delta t}{a_{w}\left(t_{j+1}\right)}}\right)
$$

where $\Delta t=t_{j+1}-t_{j}$ and the following approximation has been used

$$
-\lambda_{i, 22}\left[\theta\left(t_{j+1}\right)-\theta(\tau)\right]=-\lambda_{i} \int_{\tau}^{t_{j+1}} \frac{d \tau^{\prime}}{a_{w}} \cong \frac{\lambda_{i}}{a_{w}\left(t_{j+1}\right)}\left(t_{j+1}-\tau\right) .
$$


Substituting (16) into (15) we obtain

$$
\begin{aligned}
\varepsilon_{i, 22}\left(t_{j+1}\right)= & e^{-\eta_{i} \Delta t} \cdot \varepsilon_{i, 22}\left(t_{j}\right)+\left[1-\frac{1}{\eta_{i} \Delta t}\left(1-e^{-\eta_{i} \Delta t}\right)\right] \hat{g}_{i}\left(\sigma_{22}\left(t_{j+1}\right)\right) \\
& +\left[\frac{1}{\eta_{i} \Delta t}\left(1-e^{-\eta_{i} \Delta t}\right)-e^{-\eta_{i} \Delta t}\right] \hat{g}_{i}\left(\sigma_{22}\left(t_{j}\right)\right),
\end{aligned}
$$

where

$$
\eta_{i}=\frac{\lambda_{1}}{a_{w}\left(t_{j+1}\right)}
$$

The total strain of each layer, given by Eq. (7), can be re-written in compact form as $\left\{\varepsilon\left(t_{j+1}\right)\right\}=\left[S_{\text {elast }}\right]\left\{\sigma\left(t_{j+1}\right)\right\}+\left\{R\left(t_{j+1}\right)\right\}$

where $\left\{R\left(t_{j+1}\right)\right\}$ vector contains the viscoelastic and the swelling strains due to moisture, as given by Eq. (7). Since vector $\left\{R\left(t_{j+1}\right)\right\}$ depends on the present stress state of the $n^{\text {th }}$ ply where $1 \leq n \leq p$, an iterative procedure must be performed within each time step until the stress state converges.

Taking into account the in-plane loads acting on the plate, the equilibrium equation in global coordinates is

$\int_{0}^{h}\{\sigma\} d x=\{N\}$

By assuming uniform stress state within each ply and by using Eqs. (19) and (20), we obtain a system of equations that allow determining the in-plane laminate strain $\{\varepsilon\}$ and the stress state $\{\sigma\}_{n}$ of the $n^{\text {th }}$ ply as

$$
\left.\begin{array}{c}
\{\varepsilon\}-\left[S_{\text {elast }}\right]_{1}\{\sigma\}_{1}=\{R\}_{1} \\
\{\varepsilon\}-\left[S_{\text {elast }}\right]_{2}\{\sigma\}_{2}=\{R\}_{2} \\
n \\
\{\varepsilon\}-\left[S_{\text {elast }}\right]_{p}\{\sigma\}_{p}=\{R\}_{p} \\
h_{1}+\{\sigma\}_{2} h_{2}+\ldots+\{\sigma\}_{p} h_{p}=\{N\}
\end{array}\right\},
$$

where $h_{n}$ represents the thickness of the $n^{\text {th }}$ ply and the subscripts indicate the ply number.

In order to avoid large systems of equations the ply stress state given by Eq. (19) can be used in Eq. (20) to obtain the following condensed system of equations 
Mintzas, A., Guedes, R.M. and Aniskevich, A. (2015) 'Stress-strain analysis of specimens subjected to tensile loading during moisture uptake', Int. J. Automotive Composites, Vol. 1, Nos. 2/3, pp.205-222.

$$
\sum_{n=1}^{p}\left[S_{\text {elast }}\right]_{n}^{-1} h_{n}\{\varepsilon\}=\{N\}+\sum_{n=1}^{p}\left[S_{\text {elast }}\right]_{n}^{-1} h_{n}\{R\}_{n}
$$

The previous formulation combined with the sorption kinetics model described in section 2.1, allows for the solution of the creep problem of a polymer plate during moisture uptake. The method described here, and resumed in the flowchart depicted in Fig. 2, was adapted from LAMFLU a FORTRAN computer program previously developed for orthotropic laminates (Guedes et al. 1998; Aniskevich \& Guedes 2009).

\section{Finite Element implementation}

In order to validate the developed programme LAMFLU described above, linear viscoelastic analyses were performed using the commercial ANSYS finite element code. Due to symmetry, only one fourth of the specimen was modelled using four node layered shell elements that can account for viscoelastic material behaviour. 40 layers were used along the specimen thickness in order to be consistent with the discretization used within LAMFLU programme. The sorption kinetics model described in section 2.1 was implemented into ANSYS parametric design language via a purpose built command script. A typical mesh of the model is shown in Fig. 3 along with the boundary conditions assigned.

\section{Case study}

Stress and strain results were obtained from the application of the proposed numerical method on a rectangular EDT-10 epoxy resin specimen with dimensions $2 \times 10 \times 150 \mathrm{~mm}$. The hygroscopic properties used for the stress/strain calculations were taken from (Aniskevich 1984), whereas the mechanical properties from (Aniskevich et al. 1992). In (Aniskevich 1984), it was shown that moisture sorption of EDT-10 resin follows classical Fick's law for a wide range of atmospheric relative humidities (i.e. $16 \% \leq \varphi \leq 98 \%$ ) with an average value of hygroscopic diffusivity of $D$ $=1.9 \cdot 10^{-6} \mathrm{~cm}^{2} / \mathrm{h}$. It was also shown that moisture sorption isotherm has a nonlinear character and can be approximated by an empirical polynomial function $w_{\infty}(\varphi)=0.0004 \varphi^{2}+0.0087 \varphi$, were both $w$ and $\varphi$ are in $\%$, with the maximum moisture content of the resin being a little less than $5 \%$.

The swelling strain was assumed to be directly proportional to the moisture content of the specimen as in (Aniskevich et al. 1992) and the hygroscopic expansion factor was $\beta=0.2 \%^{-1}$. This roughly gives $1 \%$ strain for a specimen fully moistened in atmosphere with $\varphi=98 \%$. The dependence of the elastic and shear moduli on moisture content was approximated by the empirical polynomial function $\frac{1}{S}=\left[3.500+0.0005067 w(t)-0.01594 w^{2}(t)\right]$ with initial values 3.5 and 1.2 GPa respectively and the Poisson's ratio was considered constant $v=0.44$. Linear viscoelastic behaviour was described with exponential creep function according to Eq. (8) which includes the moisture-time superposition principle with the parameters of the relaxation spectrum given in Table 1.

Horizontal moisture shift factor was determined from the direct creep experiments performed in (Aniskevich et al. 1992) and approximated by the following expression: 
Mintzas, A., Guedes, R.M. and Aniskevich, A. (2015) 'Stress-strain analysis of specimens subjected to tensile loading during moisture uptake', Int. J. Automotive Composites, Vol. 1, Nos. 2/3, pp.205-222.

$a_{w}=\exp \left[-2.0680 w(t)+0.1720 w^{2}(t)\right]$. All the properties of the resin were obtained as functions of the moisture content $w(t)(\%)$ under stationary conditions.

\section{Results and discussion}

Moisture sorption process was modelled both for stationary and oscillating environments. Figures $4 \mathrm{a}$ and $4 \mathrm{~b}$ show the moisture content versus time variation for three plies that lie at normalized distance $x / h=0.025,0.225$ and 0.475 from the outer surface of the specimen and are subjected to stationary and oscillatory moisture conditions respectively. In Fig. 4a the moisture content variation has been calculated for a specimen subjected to constant atmospheric humidity $\varphi=95.8 \%$ corresponding to $w_{\infty}=4.5 \%$. It should be noted that despite the small specimen thickness (i.e. $h=2 \mathrm{~mm}$ ), over 10000 hours are needed for moisture equilibrium to be attained and thus for swelling stresses to attenuate.

In Fig. 4b, the moisture content variation has been calculated for a specimen subjected to an oscillatory atmospheric humidity corresponding to moisture content of the following form: $w(t)=1.5 \sin (2 \pi / 336 t)+3$. It can be seen that as we move towards the inner plies of the specimen, the moisture oscillation amplitude is damped. In particular, for the specimen thickness and the oscillatory period considered in this study (i.e. $h=2 \mathrm{~mm}$ and $T=336$ hours), the moisture content of the middle ply is solely affected by the stationery moisture component.

Moisture induced stresses in the specimen section change with time following moisture concentration. Figures $5 \mathrm{a}$ and $5 \mathrm{~b}$ show the variation of the normalized transverse $\left(\sigma_{z z} / \sigma_{\infty}\right)$ and longitudinal $\left(\sigma_{y y} / \sigma_{\infty}\right)$ stresses across the plate thickness as calculated at time instants $t=277$ and $2777 \mathrm{~h}$ respectively. These results correspond to a specimen subjected to uniform tensile load $\sigma_{\infty}$ (see Fig. 3) and constant atmospheric humidity $\varphi=95.8 \%$ (see Fig. 4a). Stresses obtained from LAMFLU are plotted with lines, whereas, those obtained from ANSYS with symbols. It should be noted that despite no external loads act along $z$-direction, a variable transverse stress profile arises across the specimen thickness at $t=277 \mathrm{~h}$ as shown in Fig. 5a. This stress profile evens out as moisture equilibrium is gradually restored within the specimen (see stress distribution at $t=2777 \mathrm{~h}$ ). A similar trend is also observed for the tensile stresses shown in Fig. 5b. In both figures, ANSYS and LAMFLU are shown to be in excellent agreement proving the developed design tool to be mathematically accurate. Moreover, LAMFLU is shown to be as time-efficient as ANSYS since the time required to obtain the solution is of the same scale (i.e. both run within minutes).

The time variations of the transverse $\varepsilon_{z z}$ and longitudinal $\varepsilon_{y y}$ strains are plotted in Fig. 6a and 6b respectively. The latter were calculated by performing elastic and viscoelastic analyses on a specimen subjected to uniform tensile load $\sigma_{\infty}=10 \mathrm{MPa}$ (see Fig. 3) and constant atmospheric humidity $\varphi=95.8 \%$ (see Fig. 4a). Once again, lines correspond to the results obtained from LAMFLU, whereas, symbols correspond to those obtained from ANSYS. Fig. 6a shows that $\varepsilon_{z z}$ strains from both elastic and viscoelastic analyses are initially compressive since the elastic term (i.e. first term in Eq. 7) dominates over the viscoelastic (i.e. second term in Eq. 7) and the swelling (i.e. third term in Eq. 7) terms. With the increase in the specimen moisture content, swelling strain starts to develop causing the sample to expand. In the elastic case, the sample continues to swell (i.e. $\varepsilon_{z z}$ strain increases) until moisture equilibrium is attained. However, in the viscoelastic case, viscoelastic compressive strains dominate over swelling strains for $t \geq 5 \cdot 10^{3}$, 
Mintzas, A., Guedes, R.M. and Aniskevich, A. (2015) 'Stress-strain analysis of specimens subjected to tensile loading during moisture uptake', Int. J. Automotive Composites, Vol. 1, Nos. 2/3, pp.205-222.

causing the specimen to contract in the lateral direction. Considering the viscoelastic model, at moisture equilibrium, the sample has laterally contracted, whereas considering the elastic one the sample has expanded. In Fig. 6a elastically and viscoelastically calculated $\varepsilon_{y y}$ strains follow the same trend. However, when viscoelastic behaviour is considered, longitudinal strains at moisture equilibrium are found to be higher than those obtained from the elastic case by a factor of four. It is therefore apparent that neglecting the moisture induced viscoelastic behaviour of polymer structures, will lead to erroneous design especially when strain based criteria are employed. Linear viscoelastic model of the material suppose that strain response of the material is linearly proportional to stress. This is why only one stress level $10 \mathrm{MPa}$ (that is below limit of linear viscoelastic behaviour of the material of $20 \mathrm{MPa}$ ) is considered in the paper, for other stress levels the response should be proportional.

Figures $7 \mathrm{a}$ and $7 \mathrm{~b}$ show the time variation of the elastic and viscoelastic transverse $\left(\sigma_{z z} / \sigma_{\infty}\right)$ and longitudinal $\left(\sigma_{y y} / \sigma_{\infty}\right)$ stresses that develop within the outer and the middle plies respectively. It should be noted that these two plies represent the two extremes with the middle ply being under tensile stresses and the outer ply being predominantly under compressive stresses. The stress variations from both elastic and viscoelastic analyses are shown to follow the same trend, however, the time instant at which they attain their maximum or minimum values differs. Moreover, during moisture uptake, viscoelastic stresses are shown to be lower in magnitude than the corresponding elastic since moisture induced viscoelastic behaviour leads to stress relief.

Oscillation of humidity in ambient environment leads to essential changes in stress - strain behaviour of the specimen. Figures $8 \mathrm{a}$ and $8 \mathrm{~b}$ show the time variation of the elastic and viscoelastic transverse $\left(\sigma_{z z} / \sigma_{\infty}\right)$ and longitudinal $\left(\sigma_{y y} / \sigma_{\infty}\right)$ stresses that develop within the middle ply of a specimen subjected to uniform tensile load and oscillatory moisture conditions (see Fig. $4 b)$.

All results presented for this case were obtained from LAMFLU as no special code was written in order for ANSYS to account for oscillatory boundary conditions. It should be noted that although the moisture content of the middle ply does not oscillate with time (see Fig. 4b), both longitudinal and transverse stresses are of an oscillatory form.

This is because the portion of the load that is carried by the middle ply depends on that carried by the other plies. Since stresses in the outer plies are of oscillatory form (due to the oscillatory moisture content shown in Fig. 4b), so should be stresses in the middle ply. From Fig 8a and 8b it is apparent that structures subjected to oscillatory moisture conditions should be designed against fatigue issues. The amplitude of the oscillating stresses that arise within the case studied is quite significant and ranges from $0.15 \cdot \sigma_{\infty}$ up to $1 \cdot \sigma_{\infty}$ for the inner and outer plies respectively. As in the case of stationary moisture conditions, both stress components as calculated from the viscoelastic analysis are lower than those calculated from the elastic one.

The corresponding time variations of the transverse $\varepsilon_{z z}$ and longitudinal $\varepsilon_{y y}$ strains are plotted in Figs. $9 \mathrm{a}$ and $9 \mathrm{~b}$ respectively. As in the case of stationary moisture conditions, both $\varepsilon_{z z}$ and $\varepsilon_{y y}$ elastic strains increase until they reach a plateau at $t \geq 8 \cdot 10^{3}$ when the stationery moisture component attains a constant value. Longitudinal $\varepsilon_{y y}$ viscoelastic strains are once again shown to be several times higher than the corresponding elastic ones. 
Mintzas, A., Guedes, R.M. and Aniskevich, A. (2015) 'Stress-strain analysis of specimens subjected to tensile loading during moisture uptake', Int. J. Automotive Composites, Vol. 1, Nos. 2/3, pp.205-222.

\section{Conclusions}

A robust and efficient numerical method for the calculation of the internal stress state that develops within structures subjected to mechanical and steady state or transient hygroscopic loading conditions has been developed. The method has been validated against finite element analyses and was shown to be mathematically accurate. Results from the application of the proposed method on an epoxy polymer binder indicate that:

- Moisture induced viscoelastic behaviour should be taken into account when designing polymer structures especially if strain based criteria are to be employed. This is because viscoelastic strains are shown to be up to several times greater (four times in this case study) than those calculated via elastic analysis.

- A variable stress profile arises within a polymer structure over a significant part of its life spam with the stresses at some time instant being several times greater (up to three times in this case study) than the externally applied stress field (i.e. the far field load).

- Structures subjected to oscillatory moisture conditions should be designed against fatigue due to the significant stress oscillation within the structure. For the epoxy case studied here, stress oscillations with amplitudes ranging from $0.15 \sigma_{\infty}$ (for the middle ply) up to $\sigma_{\infty}$ (for the outer ply) were found.

Due to the iterative procedure of the developed method, viscoplastic material behaviour can be incorporated in a straight forward manner. The study of the viscoplastic response of polymer structures subjected to tensile loading under moisture uptake will be the subject of a future publication. It is also evident that given research and obtained results do not pretend to general conclusions. One should keep in mind that the epoxy resin under a consideration is a typical representative of the epoxies, absorb little less than 5\% moisture during more than one year, and was considered only as a model material. Behaviour of hydrophilic materials, or strongly swelling materials, or anisotropic materials may be essentially different.

Acknowledgement. Andrey Aniskevich acknowledges ESF project

No. 2013/0017/1DP/1.1.1.2.0/13/APIA/VIAA/063 for the financial support.

\section{References}

Aniskevich, A.N., 1984. Experimental study of sorption of moisture in EDT-10 epoxy binder. Mechanics of Composite Materials, 20(6), pp.670-673. Available at: http://www.scopus.com/inward/record.url?eid=2-s2.0-5544273813\&partnerID=tZOtx3y1 [Accessed March 25, 2014].

Aniskevich, A.N., 1986. Moisture absorption and desorption by a unidirectional organoplastic under steady temperature-humidity conditions. Mechanics of Composite Materials, 22(3), pp.383-388. Available at: http://www.scopus.com/inward/record.url?eid=2-s2.034250103545\&partnerID=tZOtx3y1 [Accessed March 25, 2014].

Aniskevich, A.N. \& Guedes, R.M., 2009. Viscoelastic stress-strain analysis during moisture uptake under tensile creep. In Proceeding of the 17th International Conference on Composite Materials (ICCM-17). p. CD F1.17. Available at: http://www.scopus.com/inward/record.url?eid=2-s2.0-80052061343\&partnerID=tZOtx3y1. 
Mintzas, A., Guedes, R.M. and Aniskevich, A. (2015) 'Stress-strain analysis of specimens subjected to tensile loading during moisture uptake', Int. J. Automotive Composites, Vol. 1, Nos. 2/3, pp.205-222.

Aniskevich, A.N. \& Jansons, J., 1998. Structural approach to calculation of the effect of moisture on elastic characteristics of organoplastics. Mechanics of Composite Materials, 34(4), pp.383-386. Available at: http://www.scopus.com/inward/record.url?eid=2-s2.00032270626\&partnerID=tZOtx3y1.

Aniskevich, A.N., Yanson, Y.O. \& Aniskevich, N.I., 1992. Creep of epoxy matrix in atmospheric humidity. Mekhanika Kompozitnykh Materialov, (1), pp.17-24. Available at: http://www.scopus.com/inward/record.url?eid=2-s2.0-0026435249\&partnerID=tZOtx3y1.

Crank, J., 1975. The Mathematics of Diffusion 2nd ed., Oxford: Clarendon Press.

Czyz, J.A. \& Szyszkowski, W., 1990. An effective method for non-linear viscoelastic structural analysis. Computers \& Structures, 37(5), pp.637-646. Available at: http://www.sciencedirect.com/science/article/pii/004579499090096K.

Glaskova, T.I. et al., 2007. A comparative analysis of moisture transport models as applied to an epoxy binder. Mechanics of Composite Materials, 43(4), pp.377-388. Available at: http://www.scopus.com/inward/record.url?eid=2-s2.0-34548738279\&partnerID=tZOtx3y1 [Accessed March 25, 2014].

Gramoll, K.C., Dillard, D.A. \& Brinson, H.F., 1989. A stable numerical solution method for inplane loading of nonlinear viscoelastic laminated orthotropic materials. Composite Structures, 13(4), pp.251-274. Available at: http://www.sciencedirect.com/science/article/pii/0263822389900111.

Guedes, R.M., Marques, A.T. \& Cardon, A., 1998. Analytical and Experimental Evaluation of Nonlinear Viscoelastic-Viscoplastic Composite Laminates under Creep, Creep-Recovery, Relaxation and Ramp Loading. Mechanics Time-Dependent Materials, 2(2), pp.113-128. Available at: http://www.scopus.com/inward/record.url?eid=2-s2.00040542460\&partnerID=tZOtx3y1.

He, Y., 2012. Moisture absorption and hygroscopic swelling behavior of an underfill material. Thermochimica Acta, 546(0), pp.143-152. Available at: http://www.sciencedirect.com/science/article/pii/S0040603112003498 [Accessed July 14, 2014].

Jones, R.M., 1975. Mechanics of composite materials, London: Taylor \& Francis.

Lin, Y.C.C. \& Chen, X., 2005. Moisture sorption-desorption-resorption characteristics and its effect on the mechanical behavior of the epoxy system. Polymer, 46(25), pp.11994-12003. Available at: http://www.sciencedirect.com/science/article/pii/S0032386105014497 [Accessed July 14, 2014].

Lykov, A., 1948. Thermal Conductivity of Nonsteady-State Processes [in Russian], Moscow/Leningrad: Energiya. 
Mintzas, A., Guedes, R.M. and Aniskevich, A. (2015) 'Stress-strain analysis of specimens subjected to tensile loading during moisture uptake', Int. J. Automotive Composites, Vol. 1, Nos. 2/3, pp.205-222.

Perov, Y.Y. \& Kruzhkova, E.Y., 1991. Influence of moisture on mechanical properties of carbon-reinforced plastics with various porosities. Mechanics of Composite Materials, 27(2), pp.144-151. Available at: http://www.scopus.com/inward/record.url?eid=2-s2.034249837311\&partnerID=tZOtx3y1 [Accessed July 14, 2014].

Perreux, D. \& Suri, C., 1997. A study of the coupling between the phenomena of water absorption and damage in glass/epoxy composite pipes. Composites Science and Technology, 57(9-10), pp.1403-1413. Available at:

http://www.scopus.com/inward/record.url?eid=2-s2.0-0031225129\&partnerID=tZOtx3y1.

Plume, E., 1994. Calculation of moisture stresses in a viscoelastic crossplied composite. Mekhanika Kompozitnykh Materialov, 30(4), pp.494-501. Available at: http://www.scopus.com/inward/record.url?eid=2-s2.0-0028475282\&partnerID=tZOtx3y1.

Plume, E.Z. \& Maksimov, R.D., 1992. Nonsteady stresses in a polymer plate induced by moisture. Mechanics of Composite Materials, 28(2), pp.114-120. Available at: http://www.scopus.com/inward/record.url?eid=2-s2.0-21144477538\&partnerID=tZOtx3y1 [Accessed July 15, 2014].

Plushchik, O.A. \& Aniskevich, A.N., 2002. Diffusion moisture sorption by an isotropic polymer material in atmosphere with stationary and nonstationary humidity. Mechanics of Composite Materials, 38(2), pp.149-162. Available at: http://www.scopus.com/inward/record.url?eid=2-s2.0-0036296897\&partnerID=tZOtx3y1.

Quino, G., El Yagoubi, J. \& Lubineau, G., 2014. Characterizing the toughness of an epoxy resin after wet aging using compact tension specimens with non-uniform moisture content. Polymer Degradation and Stability, 109, pp.319-326. Available at: http://www.scopus.com/inward/record.url?eid=2-s2.0-84907315138\&partnerID=tZOtx3y1 [Accessed October 7, 2014].

Schapery, R.A., 1974. Viscoelastic behavior and analysis of composite materials, Available at: http://www.scopus.com/inward/record.url?eid=2-s2.0-0016370135\&partnerID=tZOtx3y1.

Shaffer, B.W. \& Levitsky, M., 1974. Thermoelastic constitutive equations for chemically hardening materials, Available at: http://www.scopus.com/inward/record.url?eid=2-s2.00016106276\&partnerID=tZOtx3y1.

Shtraus, V.D., 1980. Calculation of provisional heredity functions by means of an inverse laplace transform. Mechanics of Composite Materials, 16(1), pp.126-130. Available at: http://www.scopus.com/inward/record.url?eid=2-s2.0-34250248846\&partnerID=tZOtx3y1 [Accessed July 15, 2014].

Weitsman, Y., 1979. Interfacial stresses in viscoelastic adhesive-layers due to moisture sorption. International Journal of Solids and Structures, 15(9), pp.701-713. Available at: http://www.scopus.com/inward/record.url?eid=2-s2.0-0018725109\&partnerID=tZOtx3y1. 
Mintzas, A., Guedes, R.M. and Aniskevich, A. (2015) 'Stress-strain analysis of specimens subjected to tensile loading during moisture uptake', Int. J. Automotive Composites, Vol. 1, Nos. 2/3, pp.205-222.

Weitsman, Y.J. \& Elahi, M., 2000. Effects of fluids on the deformation, strength and durability of polymeric composites - an overview. Mechanics Time-Dependent Materials, 4(2), pp.107-126. Available at: http://www.scopus.com/inward/record.url?eid=2-s2.00033710422\&partnerID=tZOtx3y1.

Yagoubi, J. El et al., 2012. A fully coupled diffusion-reaction scheme for moisture sorptiondesorption in an anhydride-cured epoxy resin. Polymer, 53(24), pp.5582-5595. Available at: http://www.sciencedirect.com/science/article/pii/S0032386112008051.

\section{Figures}

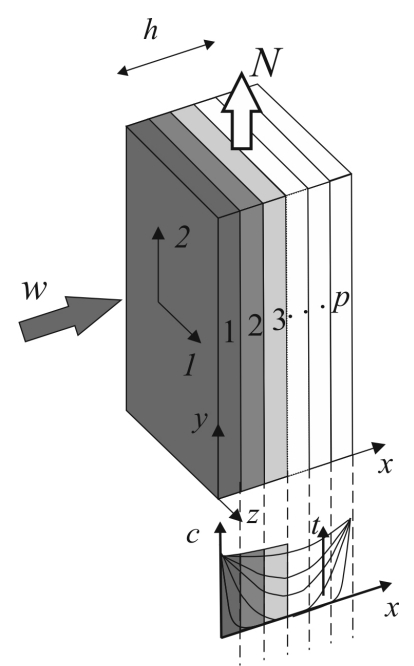

Fig. 1. Graphical illustration of a specimen divided into $p$ plies with different material properties corresponding to the different ply moisture contents. 
Mintzas, A., Guedes, R.M. and Aniskevich, A. (2015) 'Stress-strain analysis of specimens subjected to tensile loading during moisture uptake', Int. J. Automotive Composites, Vol. 1, Nos. 2/3, pp.205-222.

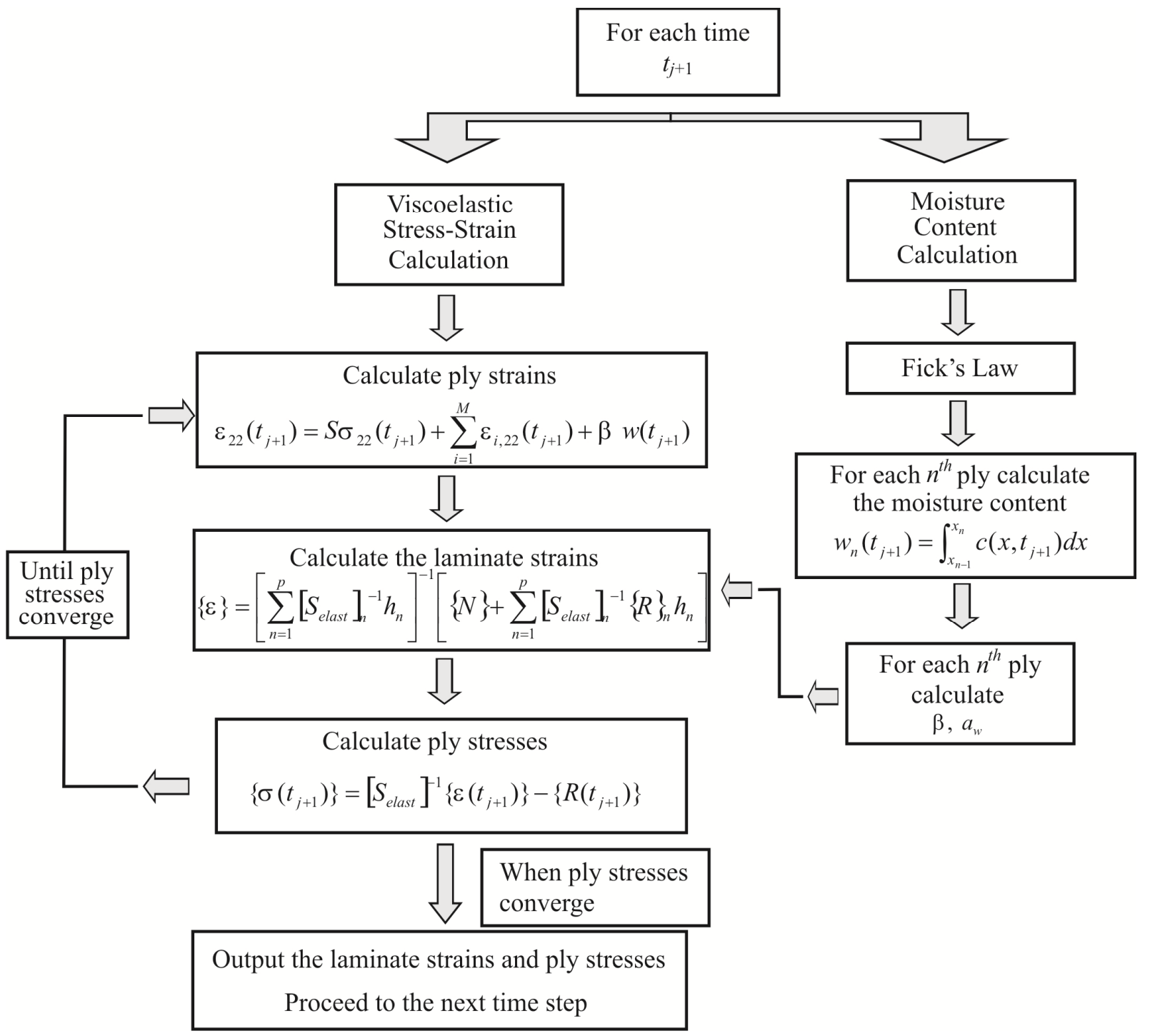

Fig. 2. Flowchart of the hygro-viscoelastic stress-strain calculation scheme. 
Mintzas, A., Guedes, R.M. and Aniskevich, A. (2015) 'Stress-strain analysis of specimens subjected to tensile loading during moisture uptake', Int. J. Automotive Composites, Vol. 1, Nos. 2/3, pp.205-222.

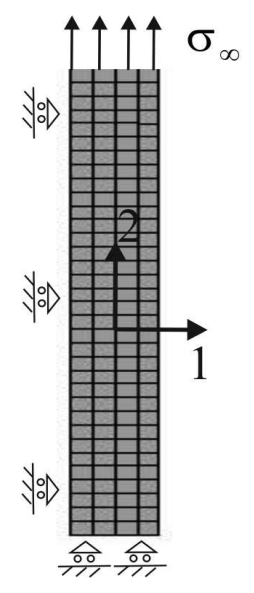

Fig. 3. ANSYS finite element model and boundary conditions applied.
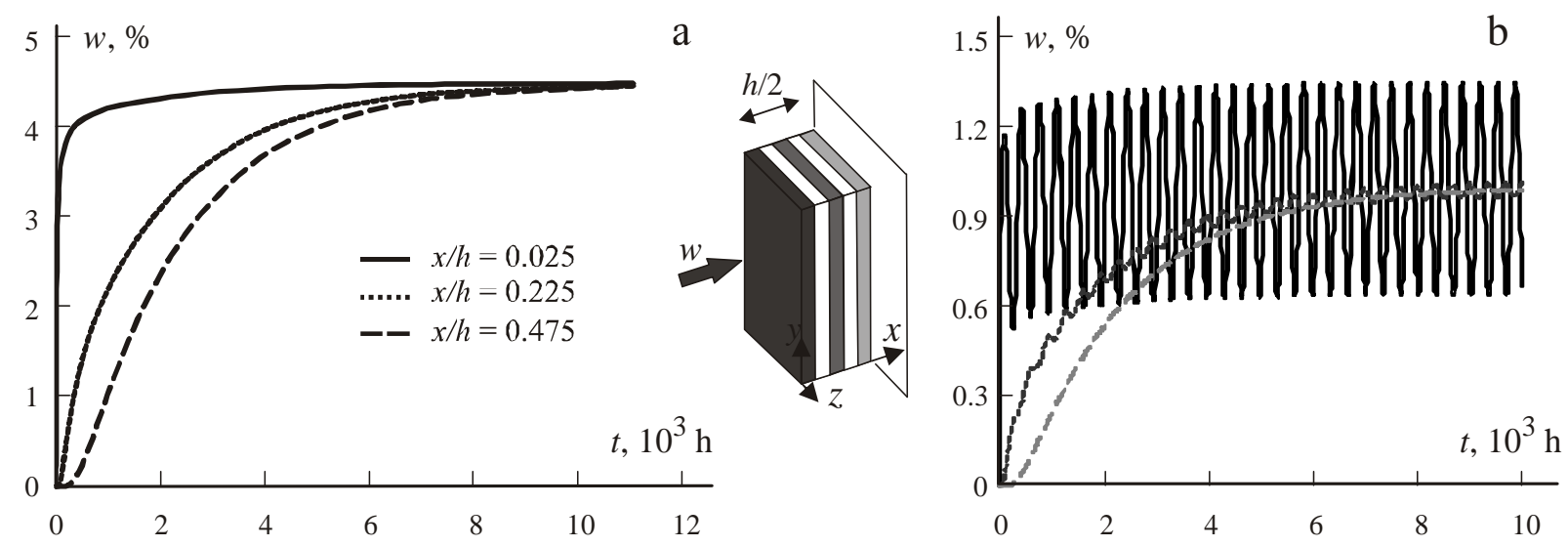

Fig. 4. Moisture content variation with time for plies that lie at normalized distance $x / h=0.025$, 0.225 and 0.475 from the outer surface of the specimen and are subjected to (a) stationary $w_{\infty}=4.5 \%$ and (b) oscillatory $w(t)=1.5 \sin (2 \pi / 336 t)+3$ moisture conditions. 
Mintzas, A., Guedes, R.M. and Aniskevich, A. (2015) 'Stress-strain analysis of specimens subjected to tensile loading during moisture uptake', Int. J. Automotive Composites, Vol. 1, Nos. 2/3, pp.205-222.

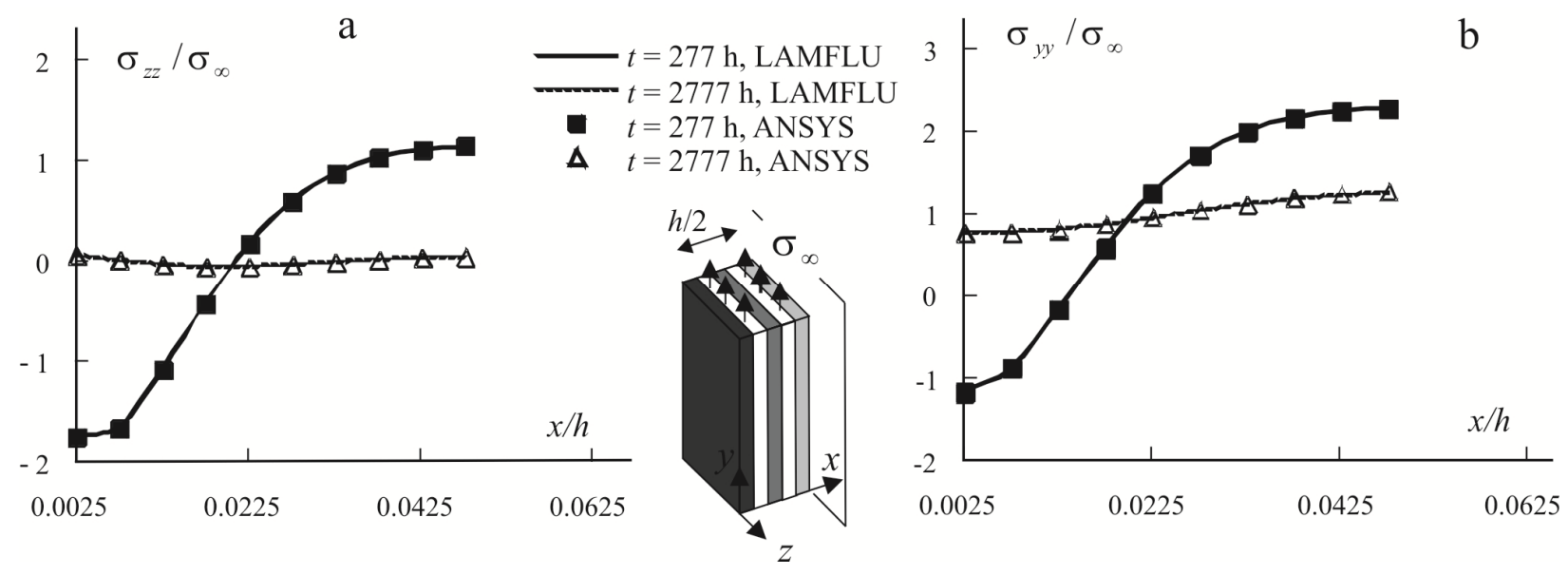

Fig. 5. Variation of the normalized viscoelastic (a) transverse $\sigma_{z z} / \sigma_{\infty}$ and (b) longitudinal $\sigma_{y y} / \sigma_{\infty}$ stresses across the specimen thickness as obtained from LAMFLU (lines) and ANSYS (symbols). The specimen is subjected to a uniform tensile load $\sigma_{\infty}$ and constant atmospheric humidity $\varphi=95.8 \%$.

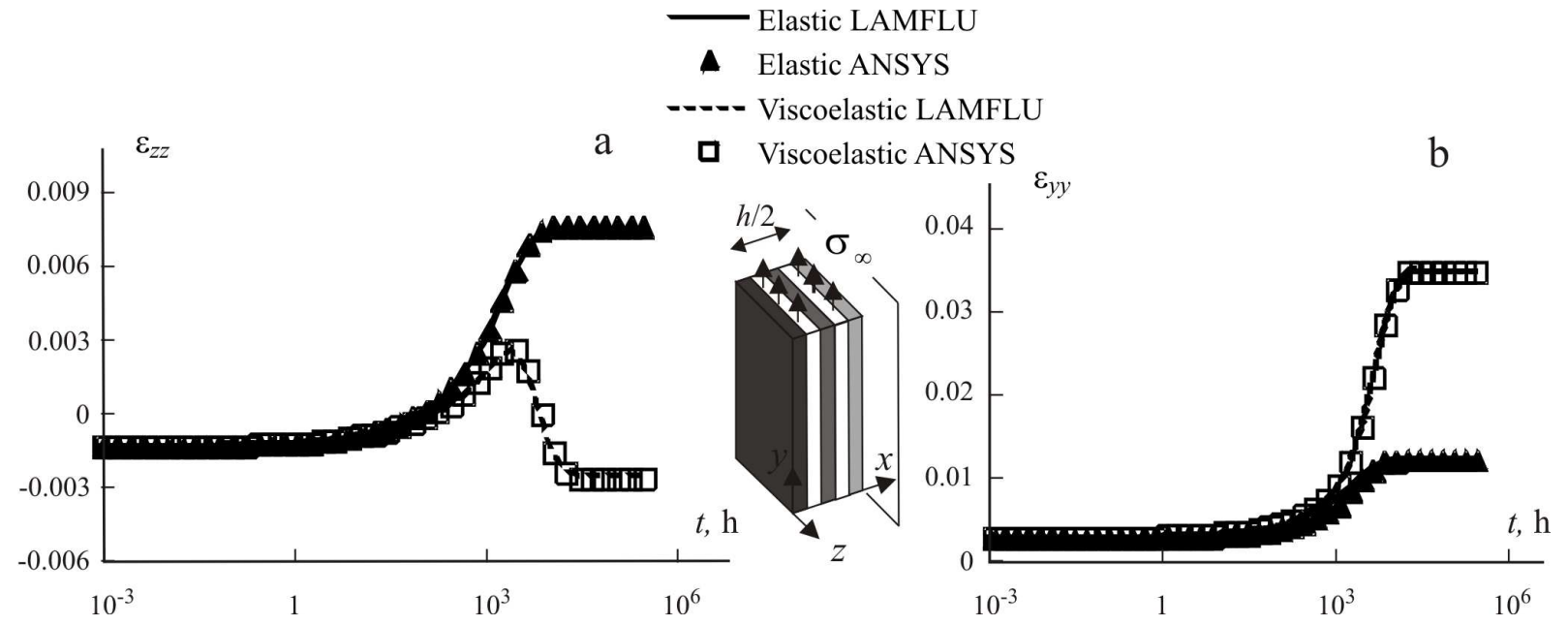

Fig. 6. Time variation of (a) transverse $\varepsilon_{z z}$ and (b) longitudinal $\varepsilon_{y y}$ strains as obtained from elastic and viscoelastic analyses performed using LAMFLU (lines) and ANSYS (symbols). The specimen is subjected to a uniform tensile load $\sigma_{\infty}=10 \mathrm{MPa}$ and constant atmospheric humidity $\varphi=95.8 \%$. 
Mintzas, A., Guedes, R.M. and Aniskevich, A. (2015) 'Stress-strain analysis of specimens subjected to tensile loading during moisture uptake', Int. J. Automotive Composites, Vol. 1, Nos. 2/3, pp.205-222.

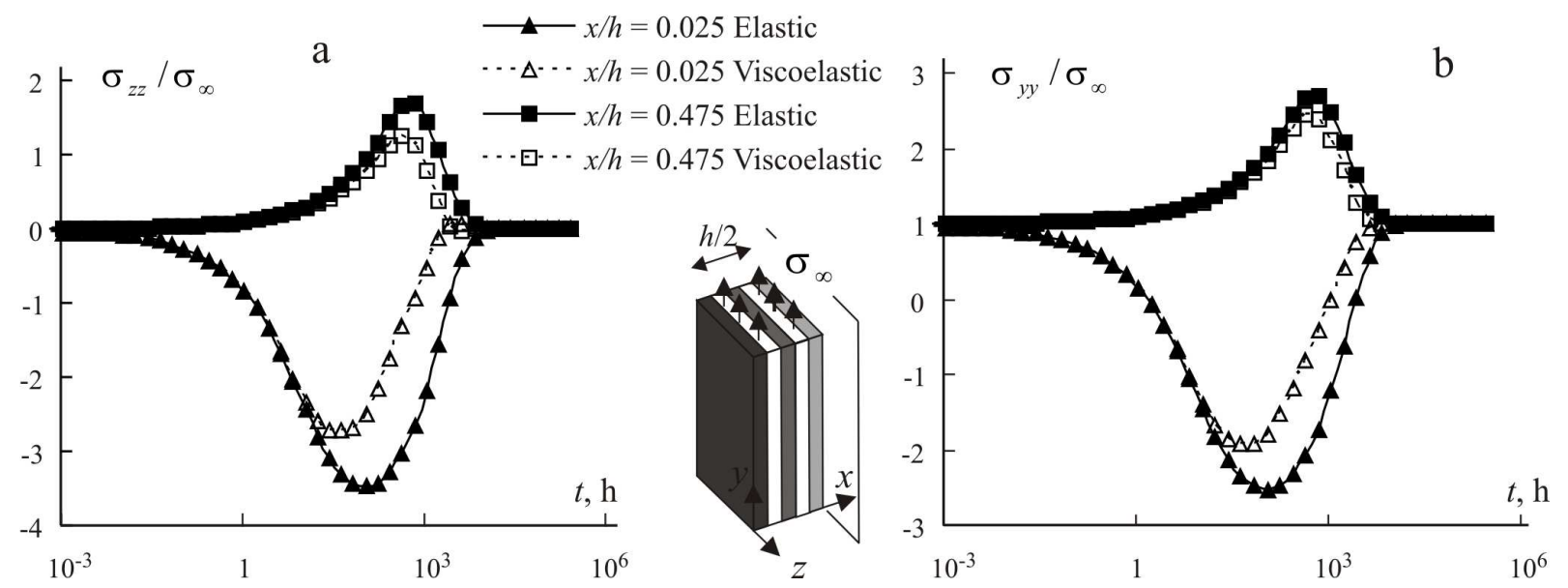

Fig. 7. Time variation of normalized (a) transverse $\sigma_{z z} / \sigma_{\infty}$ and (b) longitudinal $\sigma_{y y} / \sigma_{\infty}$ stresses as obtained from elastic (solid lines, black symbols) and viscoelastic (dashed lines, white symbols) analyses. The specimen is subjected to a uniform tensile load $\sigma_{\infty}$ and constant atmospheric humidity $\varphi=95.8 \%$.
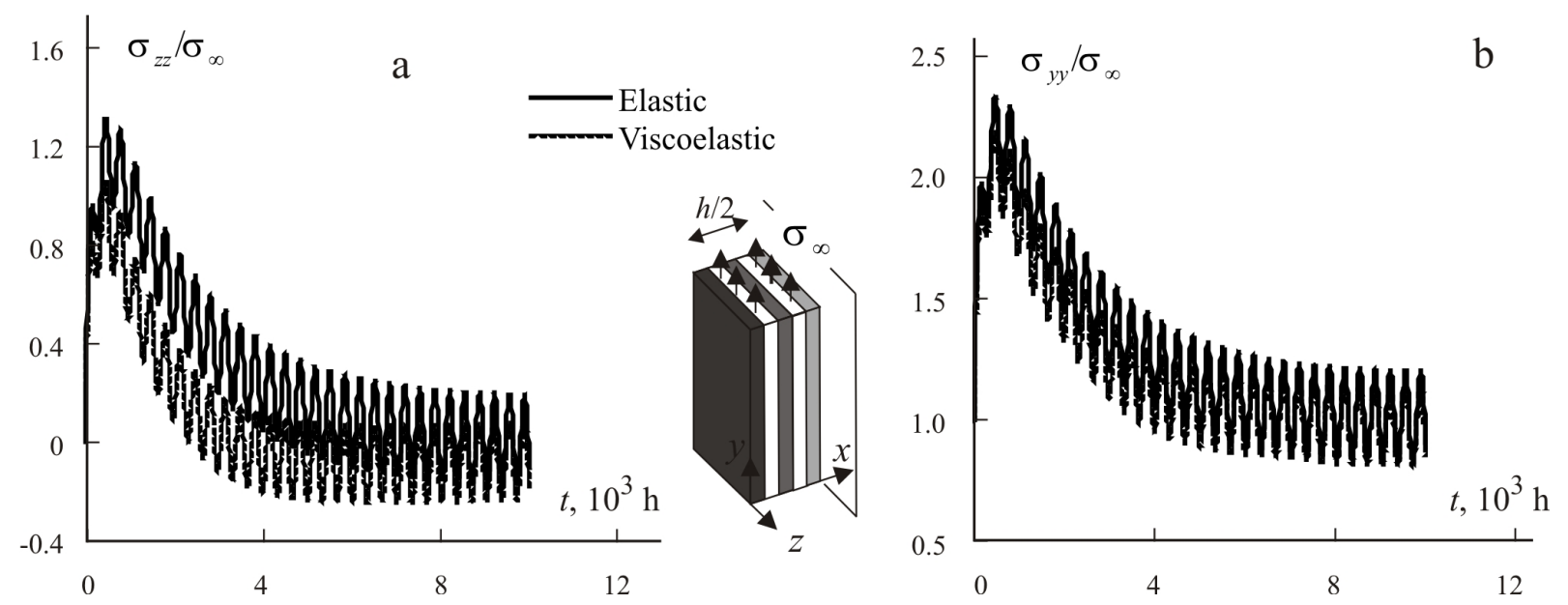

Fig. 8. Time variation of the normalized elastic (solid lines) and viscoelastic (dashed lines) (a) transverse $\sigma_{z z} / \sigma_{\infty}$ and (b) longitudinal $\sigma_{y y} / \sigma_{\infty}$ stresses at $x / h=0.475$ for a specimen subjected to oscillatory moisture conditions $w(t)=1.5 \sin (2 \pi / 336 t)+3$. Results are obtained from LAMFLU. 
Mintzas, A., Guedes, R.M. and Aniskevich, A. (2015) 'Stress-strain analysis of specimens subjected to tensile loading during moisture uptake', Int. J. Automotive Composites, Vol. 1, Nos. 2/3, pp.205-222.
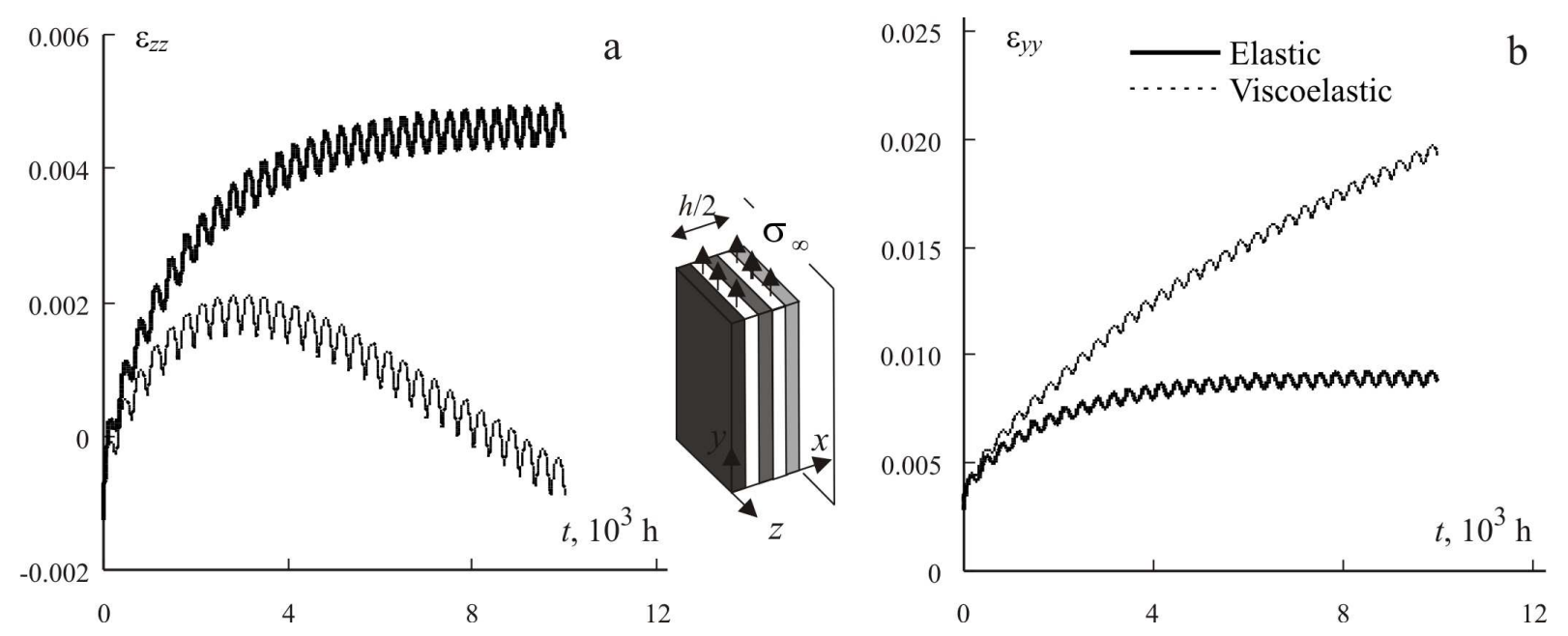

Fig. 9. Time variation of elastic (solid lines) and viscoelastic (dashed lines) (a) transverse $\varepsilon_{z z}$ and (b) longitudinal $\varepsilon_{y y}$ strains for a specimen subjected to a uniform tensile load $\sigma_{\infty}=10 \mathrm{MPa}$ and to oscillatory moisture conditions $w(t)=1.5 \sin (2 \pi / 336 t)+3$.

\section{Tables}

Table 1. Parameters of relaxation spectrum obtained from (Aniskevich et al. 1992)

\begin{tabular}{lll}
\hline$i$ & $\lambda_{i}, \mathrm{~s}^{-1}$ & $S_{i}, \mathrm{MPa}^{-1}$ \\
\hline 1 & $8.272 \cdot 10^{-05}$ & $2.89 \cdot 10^{-06}$ \\
2 & $2.051 \cdot 10^{-07}$ & $5.23 \cdot 10^{-05}$ \\
3 & $5.603 \cdot 10^{-09}$ & $1.83 \cdot 10^{-04}$ \\
4 & $2.789 \cdot 10^{-10}$ & $5.03 \cdot 10^{-04}$ \\
5 & $1.870 \cdot 10^{-10}$ & $1.53 \cdot 10^{-03}$ \\
\hline
\end{tabular}

